\title{
The Traces of Objects - A Survey of Teaware-related Materials in the Literature of Song Dynasty
}

\author{
Li Yang \\ Cultural Communication and Design, Zhejiang University of Finance \& Economics Dongfang College, Jiaxing, China
}

\section{Email address: \\ 429716857@qq.com}

\section{To cite this article:}

Li Yang. The Traces of Objects - A Survey of Teaware-related Materials in the Literature of Song Dynasty. International Journal of Education, Culture and Society. Vol. 5, No. 4, 2020, pp. 62-69. doi: 10.11648/j.ijecs.20200504.11

Received: April 22, 2020; Accepted: June 11, 2020; Published: July 6, 2020

\begin{abstract}
I write this essay to re-examine the history of "objects" and trace the historical trajectory of them as an "experiencer," which provides much food for thought on Chinese's current way of life. This kind of thinking does not mean recapturing the attitude of the Song people towards tea ware, but means researching the evolution of "tea ware" from Tang to Song and the influence of the evolution on the present. This may be a valuable guide to exploring the philosophy of Medieval China. Firstly, in this study, the corpus of ancient books in Song Dynasty is established with the utilization of literature investigation. In this process, the basic concepts and theoretical problems in tea ware ancient books in Song Dynasty have been sorted out and discussed with the utilization of relevant theoretical research methods, including philology, linguistics, history, bibliography, editology, art and so on. Secondly, relevant collected information is sorted out and summarized, including document titles, compilers, content summary, categories, various versions and so on. These ancient books of tea ware in Song Dynasty are listed in chronological order by drawing tables. Thirdly, the definitions of the relevant literature are listed through the method of induction and comparison. After comparing similarities and differences, own opinions are put forward. By summarizing the characteristics of tea ware in tea ware literature in different periods of the Song Dynasty, the formation and development of tea ware design ideas in the Song Dynasty are further explored. In the final analysis, I conclude that Cai Xiang (蔡襄) played a pivotal role in the teaware development in the Northern Song dynasty (北宋) and even the entire Song dynasty (宋代). Under his influence, the teaware-making aesthetics of the Song dynasty was dominated by teaware from Jian Kiln.
\end{abstract}

Keywords: Song Dynasty, Literature, Teaware, Materials

\section{Introduction}

In the Song dynasty, manufacturing techniques of porcelain, silverware and ironware among other objects had reached the apogee of their development. As a matter of fact, the invention and spread of printing with movable type greatly facilitated the recording of people's thoughts and profoundly shaped their attitude towards texts, learning and Nature. No wonder all social strata in the Song dynasty pursued the opulent tea ware with unprecedented ardency and fervor, and indulged in those things that had been considered absurd and ridiculous in the previous dynasty. Ouyang Xiu (欧阳修), for instance, says in the Preface to Jigu lu (集古录) (Collected Records of the Past), "I can only say, by way of reply, that doing so supplies me with what I enjoy. What harm is there if I grow old amusing myself with these things?" [1] Literary colossus Su Shi (苏轼) explained why the scholar had that opinion in
“Tower of Transcendence” (超然台记), “All things (wu) have something in them that is worth looking at. Anything that is worth looking at may bring joy, it need not be extraordinary, imposing, or ornate." [1] Indeed, it's such enjoyable features that make people like Su Shi and Ouyang Xiu enjoy those things really. In this case, the beauty of things and the ease of mind are no longer distinguishable.

Before writing this essay, I have made some assumptions. For example, different types of tea cups, such as porcelain, golden, silver, and glass cups, were used by different social strata in Song dynasty. But with further exploration, I came to realize that almost none of my previous assumptions holds true. The people in the Song dynasty had completely different opinions of teaware from ours. Despite regarding tea cups from Jian'an (建安) (now Jian'ou, Fujian) Kiln as the insurmountable height of teaware-making, we speak more highly of those objects from the dynasty's Top 5 Kilns-Guan 
or Official (官) Kiln, Ge (哥) Kiln, Ru (汝) Kiln, Ding (定) Kiln and Jun (均) Kiln. There is an exaggerated statement that even a large pile of money pales in comparison with a little piece of porcelain from Ru Kiln. But such a record can seldom be found in teaware-related literature of the Song dynasty. Cai Xiang's high praise of Jian Kiln's tea cups earned the then incumbent Emperor Huizong's recognition and naturally became a mainstream fashion in tea-drinking. Hence, the kiln's tea cups were considered top items for collection in their own right. Even so, Cai Xiang despised other kilns' objects that were adored greatly by many other scholars in that dynasty. For this reason, I think it necessary to reconsider the status of the top 5 kilns in the hearts of the people of the Song dynasty and thus establish new presumptions that have been urging me to give a clearer picture of what role the teaware played in people's daily life in the Song dynasty with the help of literature on teaware. Anyway, I'm writing this essay not to investigate the tea itself or the history of tea. But in such investigation, I inevitably touch on various aspects of the traditional tea culture. From the Song dynasty onwards, tea culture unexceptionally evolved in response to the shift of public taste and interest and further adapted itself to Chinese aesthetics. In this essay, I simply examine teaware-related literature to discover the dynasty's new values and new outlook on teaware as well as the dynastic scholars' efforts in proposing that outlook. Before the Song dynasty, these opinions could never have been considered worthy of promotion from a political or moral point of view or an aesthetic point of view. However, all this had changed in the Song dynasty, when scholars believed that objects could showcase not just a kind of beauty, but even an imprint of life. Today most teaware artisans in that dynasty have fallen into oblivion, but their design ideas and concepts have played a significant role in teaware making today.

As tea culture reached its heyday in the Song dynasty, I simply want to explore how the teaware of the Song dynasty embodied Chinese mainstream thoughts by tracing the design ideas behind such objects. Examining various kinds of teaware-related literature enables me to analyze the ideological cornerstone of the teaware and establish the basis of teaware design, which may inspire contemporary teaware makers. Besides, present-day teaware makers could take a deeper dive into the genuine traditional tea culture.

The modern technique helps me build up a corpus and search keywords therein so that various relevant materials can be readily collected to the most accurate extent possible. On a basis of the law of their distribution, I probe into the exact meanings, connotations and denotations of these materials.

\section{Materials on Teaware in Literature of the Song Dynasty}

Almost every social stratum in the Song dynasty create writings on teaware, from which we can get a glimpse into their thoughts. Emperor Huizong, namely Zhao Jie (赵佶), composes Daguan chalun (大观茶论) (Treatise on Tea in the
Daguan Era); famous official Cai Xiang promotes in his Chalu (茶录) (Records of the Tea) the Beiyuangongcha 北苑贡茶 (Beiyuan Gardens' Tribute Tea) of Jian'an and relevant porcelain teaware to the incumbent emperor as such objects has never been mentioned in Lu Yu's (陆羽) Chajing 茶经 (Classic of Tea); graduate scholar Huang Ru (黄儒) also writes Pinchayaolu (品茶要录) (Account of the Essentials of Tea Sipping) in the year of 1075; another scholar Tang Geng 唐庚 writes Doucha ji 斗茶记 (Record of Tea Contests); Xiong Fan (熊蕃) and Xiong Ke (熊克) coauthors Xuanhe beiyuan gongcha lu (宣和北苑贡茶录) Record of the Beiyuan Garden Tribute Tea in the Xuanhe Period; Zhao Ruli (赵汝砺), Transport Commissioner of Fujian, records the Jian'an chayuan (建安茶园)'s (Jian'an Tea Gardens) procedures on plucking the tribute tea in Beiyuan bielu (北苑 别录) (Other Records of Beiyuan Garden Tea). Besides, a common old man called Shen'an (审安) composes Chaju tuzan (茶具图赞) (An Illustrated Guide to Tea Utensils), the earliest of its kind ever written in China.

The Song dynasty's literature including encyclopedias, historical sources, and causeries have left behind a large body of materials about teaware. First, encyclopedias such as Taiping yulan (太平御览) (Imperial Readings of the Taiping Era), Cefu yuangui (册府元龟)(The Prime Turtle of the Record Bureau), Tai ping guangji (太平广记) (Extensive Records of the Taiping Era), and Wenyuan yinghua (文苑英华) (Finest Blossoms in the Garden of Literature). Second, official history records including compendiums, notes on the daily life of emperors, current political records, calendars, and veritable records, as well as state history books such as Songshu (宋书) (The Book of Song), Zizhi tongjian (资治通鉴) (The Comprehensive Mirror for the Aid in Governance), unofficial histories, and anecdotes. All these sources provide us with an immense number of materials. Besides, Songshi (宋史) (The History of the Song), is worth noticing because it gives a fundamentally correct panorama of the dynastic society despite the fact that it was authored by the Yuan Dynasty scholars. The "Records of Foods and Commodities" (食货志) and "Records of Literature and Art"(艺文志) chapters of the history are of special importance because they elaborate on the government's culture and policy of tea and teaware.

Also, Song Dynasty scholar-officials mention teaware more or less in their causeries, poems and other literary genres. For example, some writers state clearly their attitudes towards teaware and their discussions on this topic in Wanling ji (宛陵 集) (Collected Works of Mei Wanling), Jiayou ji (嘉佑 集)(Collected Works of the Jiayou Period), Yuzhuang huangxiansheng wenji (豫章黄先生文集) (An Anthology of Yuzhang Master Huang's Writings), Wenguo wenzheng sima gong wenji (温国文正司马公文集) (Collected works of Sima Guang the Duke of Wenzheng) and Suwen qishang (苏文奇赏) (Selected Essays of Su Shi).

\subsection{Materials in the Northern Song Dynasty}

Ding Wei (丁谓) was probably the first teaware essayist in the Song dynasty. It's a great pity that all his writings have been lost and we can only infer what he says from indirect 
sources such as Chalu (茶录), Xuanhe beiyuan gongcha lu (宣和北苑贡茶录), Junzhai dushu zhi (郡斋读书志) (Records of a Prefect's Reading and Thoughts), and Tiaoxi yuyin conghua (苦溪渔隐从话) (Assembled Remarks by the Fisherman Recluse of Tiao Creek). Ding Wei worked as Transport Commissioner of Fujian during the Zhidao Period (995-997) of Emperor Taizong. The official writes essays on Jian Tea, a brief name of the iconic Beiyuan Gardens' Tribute Tea. According to Cai Xiang, that book is called Chatu (茶 图)(Pictures on Tea) and in his book, Ding Wei mainly describes the expertise of plucking and making the Beiyuan Gardens' Tribute Tea; Chao Gongwu (昆公武) argues that in Junzhai dushu zhi (郡斋读书志) Ding's book is called Jian'an chalu (建安茶录) (Records of the Jian'an Tea), in which there are writings on teaware designs; Xuanhe beiyuan gongcha $l u$ (宣和北苑贡茶录) claims that Ding's work is Chalu's (茶录) chapters on lamian cha (腊面茶) spiced and oiled tea buds. The author merely mentions two tea poems in Tiaoxi yuyin conghua (莒溪渔隐丛话). The above sources denote that Ding's book mainly introduces the plucking and making of the Beiyuan Gardens' Tribute Tea and includes drawings of teaware. It is yet to be confirmed whether Jian'an chalu (建安茶录) and Chalu (茶录) point to the same book.

Cai Xiang followed in the footsteps of Ding Wei by writing Chalu (茶录). During his service as Transport Commissioner of Fujian, Cai Xiang surveyed tea-making and teaware-making at length. He not only invented the Xiaotuanlongcha (小团龙茶) Little Round Dragon Tea (one of the most famous types of Jian'an tea), but also prepared a set of standards for Jian'an tea, teaware materials and usage. He took various actions to popularize the tea and teaware. His monograph proposes the nine objects of tea ceremony: chabei (茶焙) tea roaster, chalong (茶笼) tea container, chazhui (茶 椎) tea pestle, chaqian (茶铃) tea dryer, chanian 茶碾 tea grinder, chaluo (茶罗) tea sieve, chazhan (茶盏) tea cup, chashi (茶匙) tea spoon, tangping (汤瓶) teawater pot.

As soon as he made it, Cai Xiang offered the Little Round Dragon Tea to the incumbent emperor and the emperor liked it very much. This emperor not only savoured the renowned tea, but also presented it to ministers, as Ouyang Xiu writes in his Inscription on Chalu (茶录),

"Emperor Renzong treasured the tea to a great extent and did not present it even to the prime minister. But at the eve of the Southern Sacrificial Ritual, the four officials of the Zhongshu (中书) Central Secretariat and the four officials of Shumiyuan (枢密院) Military Affairs Bureau were granted a teacake decorated with court maids' hand-painted dragon, phoenix, flower and grass patterns. All the eight families got their shares but none of them dared to grind the teacake pieces because they were too rare and precious. Occasionally, they would take the cakes out to show distinguished guests. When I entered into the Imperial Bright Hall in the 7th Year of the Jiayou Period, I also got such a teacake at the eve of the sacrifice that even today I still cherish it very much. Since I became a censor more than 20 years ago, I had obtained only a single teacake." [2]

The above record shows us how precious the teacake was back then. Obviously, Little Round Dragon Tea was a top rarity during Renzong's reign. The emperor's recognition, the palace maids' intricate craftsmanship and the ministers' enjoyment make it much more than a mere drink.

Having savoured the Beiyuan tea, the emperor composes Daguan chalun (大观茶论) that describes seven types of teaware in succession: tea sieve and grinder, tea cup, xian (笔) tea brush, ping (瓶) pot, biao (构) dipper, bei lou (焙管) oven and jiuqi zhuqi (久漆竹器) lacquered bamboo object. All the objects correspond with Cai Xiang's record but for tea brush and tea dipper. Cai Xiang and Zhao Jie roughly followed the same sequence of tea objects. The former considers it appropriate to make tea and then hoard it for use while the latter puts hoarding tea behind all other steps in the natural order. Cai Xiang's monograph is in fact an exposition on procedures of plucking and making the Beiyuan Gardens' Tribute Tea and relevant teaware. The exposition falls into two parts, the first part depicting the color, fragrance and taste of the tea, the second part introducing various kinds of teaware. In contrast, Zhao Jie conducted a philosophical and metaphysical investigation on the tea in his Daguan chalun (大观茶论) in line with the prevailing Chinese concept of tian ren he yi (天人合一) human-heaven oneness. That is to say, tea-plucking, making and sipping are no longer separated, but inseparable from one another. In this case, hoarding will not be needed unless the tea is sipped. So, we can argue that Zhao Jie added this concept to the whole process and started to focus on teaware. In addition, this emperor applied the above concept in practice.

The brush and dipper, neither of which is mentioned in Chalu (茶录), were necessary tools for the tea whisking in the Song dynasty. However, it does not mean that the official and his emperor had dissimilar practices in tea-sipping. Cai Xiang first introduced the means of the tea-whisking in Part I of Chalu (茶录), and Zhao Jie proposed a systematic theory, making the shape designs of the teaware a set of official standards in this aspect.

Apart from Cai Xiang himself, his cousin Cai Jing (蔡京) modified the tea code of the Song dynasty, stipulating the sizes and shapes of containers or cases used for transferring tea. Cai Jing's son Cai Tao (蔡绦) expounded how Cai Xiang had contrived the Beiyuan Gardens' Tribute Tea in Tieweishan congtan (铁围山丛谈) (Collected Conversations at Iron-Fence Mountain).

Cai Xiang offered the Xiaotuanlongcha (小团龙茶) Little Round Dragon Tea to the incumbent emperor and his friends. Mei Yaochen (梅尧臣) writes in "Thank Cai Junmo for His Tea Gift Following the Rhythm of Mr Du's Poem” (依韵和杜相公 谢蔡君谟寄茶), "With a fragrance pervading the entire Middle Capital, thncee round tea is introduced in Grand Preceptor's house." [3] In these lines, the poet praises highly the fragrant Jian tea. The poet had sniffed its fragra when he still walked outside the courtyard. Junmo is the courtesy name of Cai Xiang.

It's obvious that the Jian'an tea had been, without doubt, the first tea brand in that dynasty. Naturally, the Song people pursued excellence in teaware-making, so that teaware became popular collectible items. Su Xiangxian (苏象先) says in Tanxun (谭训) (The Family Instruction),

"There is a monk who has a wonderful rabbit-hair pattern cup. 
Cai Xiang heard the news and tried every means to have a look at it. In the end, he saw the cup personally and was fascinated by its beauty. Then he asked, 'Could this object be used for sipping tea?' Instantly, the collector felt appalled, 'I've collected this object for decades. And I just take it out occasionally for fun. How can I allow it to be polluted by water?' Later on, he knew another monk around Xiangyang and Dengzhou had a really rare gourd and visited him to have a look. Likewise, he asked, 'Could it be used to grind tea?' The monk felt astounded, 'No, it can only be appreciated. Once it grinds tea, this rare utensil will be blemished and I will feel upset definitely.' Cai Xiang sighed, 'The cup can't brew tea and the gourd can't grind tea. What's the use of these objects? In this world, there are too many useless things like them!"' [4]

The full name of The Family Instruction is Chengxiang weigong tanxun (丞相魏公谭训) (The Family Instruction of Prime Minister the Duke of Wei). Su Xiangxian writes down the instructions of his grandfather Su Song (苏颂) 40 years after $\mathrm{Su}$ Song's death. This book mainly introduces the crux of statecraft and the code of daily behaviors. In terms of the book, a monk treasured his tea object greatly and the author spoke in the name of Cai Xiang to the effect that any tea object would mean nothing if not used. Actually, the writer explicitly expresses his grudges over those empty men from a Confucian point of view. But this record proves that back in the Northern Song dynasty, teaware had become an independent object of aesthetic appraisal.

Under Huizong and Cai Xiang's influence, Jian tea and teaware had led the fashion, thus outshining many other kinds of tea. As a result, anyone who knew well the lore of tea would venerate the white Jian tea and the black Jian teaware without exception. Fan Zhongyan (范仲淹) mentions in his lines “an emerald cup" and "turquoise foams," which refer to celadon porcelain tea cup and green tea water. However, Hu Shunzhi (胡舜陟 ${ }^{1}$ ) questions Fan's depiction in Hu Shaoshi zongji (胡 少师总集) (Complete Works of Hu Shunzhi),

"The Five Dynasties poet Zheng Ao writes in his poem, 'Delicate buds are fragrant and ethereal. So, I believe these buds are the essence of herbs! At night, the tea buds can be pestled in the mist. In winter, they can be brewed in an oven against the snow. What I fear most is that the verdant powder may scatter. At times I see green water foaming. Oh, there is nothing more precious! Just a taste of this nectar will make me feel refreshed.' Fan Wenzheng, another name of Fan Zhongyan, writes alike, 'Green clouds of dust soar over an golden grinder, and turquoise foams roll in an emerald cup.' White tea is definitely the most precious tea. Why both of them described it as verdant or green?" [5]

The writer of the above paragraph tells us that the Five Dynasties and the Early Song period were habitually predominated by green tea and celadon porcelain cups, that $\mathrm{Hu}$ Shunzhi had little knowledge of tea and thus had not hear of green tea, and that Hu Shunzhi knew little of the dominant little-round dragon tea or Jian Kiln's cups, let alone rabbit-hair

1Hu Shunzhi (胡舜陟) (1083-1143), also called Ruming, was a graduate scholar during the Daguan Era of Northern Song dynasty. In his late years, Hu called himself sanshan laoren (三山老人). pattern cups. For these reasons, Fan Zhongyan's lines were questioned by his contemporaries and should be changed according to their opinions. In his Qingsuo gaoyi qian ji (青琐 高议前集) (Lofty Deliberations of the Green Window-Lattice: Part I), Liu Fu (刘斧) records such an anecdote,

"Fan Wenzheng's A Song of Plucking Tea has become famous far and wide. Once Cai Xiang met Fan Wenzheng and asked, 'Dear sir, your tea-plucking song now has a household name. But I have a question. Perhaps that's because you wrote boldly and neglected some details.' Fan then felt confused, 'What do you mean?' Cai Xiang replied, 'Your song has two lines-'Green clouds of dust soar over a golden grinder, and turquoise foams roll in an emerald cup. Now white tea is no doubt the best tea. Instead, green tea is a low product. I dare to suggest changing your lines a bit.' Fan Wenzheng thanked him, 'Oh, that's my blunder. You are truly expert at tea! How would you change them?' Cai Xiang said, 'I just want to change two words.' 'Which words?' 'Green and turquoise.' 'Ok.' Fan Wenzheng nodded his approval. So, Cai Xiang changed the lines into 'Jade clouds of dust soar over a golden grinder, and white foams roll in an emerald cup." [6]

In his middle Northern Song dynasty book, Liu Fu records the dialogue between Cai Xiang and Fan Zhongyan. This anecdote shows us the overwhelming influence of Jian tea in those years no matter whether it was authentic or not.

Some scholar-officials went as far as to transform other tea types according to the standards of Jian Tea. Mei Yaochen describes the process in "A Poem Written upon Receiving Lei Taijian's Mengding Tea” (得雷太简自制蒙顶茶),

"In Lu Yu's Chajing, Mengding Tea is no doubt the best tea.

Today only Jianxi's round tea can be compared with it.

Also, Guzhu and Yangxian abound in excellent tea.

Recently, the southern people bragged about their curled Shuangjing tea.

Apart from the above teas, there is almost no good tea.

Sichuan's late tea is tasteless and does not deserve high praise.

Through Lei's effort, the new tea with dew is plucked.

A drinker can boil and roast it, then he should grind it a short while.

The delicate water foams and the fragrance is fresh. It was presented to Hanlin Scholars and then Erudites. He promised drunkenly but regretted when he's sober. Considering their friendship, he kept his promise boldly. He presented the tea after wrapping it with a wax bag. Alas, both tea and whip are so unfortunate to be used by me! As I am penniless, these rarities will have no use." [3] Lei Taijian (雷太简) is not mentioned in Songshi (宋史), but his identity can be initially confirmed as an official according to Mei Yaochen's poem "Send off Lei Taijian to Guozhou” (送雷太简知虢州). Besides, Northern Song scholar-officials imply Lei's close connections with them in Jiayou ji (嘉佑集), Yuzhuang huangxiansheng wenji (豫章黄 先生文集),Wenguo wenzheng sima gong wenji (温国文正司 马公文集) and Suwen qishang (苏文奇赏). The above poem indicates three points: first, Mengding Tea prevailed from the 
Tang dynasty (唐代) through the Five dynasties (五代), but declined in the Song dynasty; second, Lei Taijian was an official and knew well how to make tea and especially Jian tea, which makes it possible for him to transform Mengding Tea with Jian Tea making techniques; third, Mei Yaochen gave high praise to the Little Round Dragon Tea made by his bosom friend Cai Xiang. When the transformed Mengding tea arrived, Mei Yaochen felt greatly pleased, as represented by his poem and an essay. That's because Mei Yaochen believed the tea transformed by Lei Taijian was better than the original tea favoured by $\mathrm{Lu} \mathrm{Yu}$. It's expected that all the teaware followed the tradition of Jian Tea.

By the unremitting efforts of Huizong Emperor, Cai Xiang and his clan, the Northern Song Dynasty official-scholars universally accepted the "white tea and black cup" as the dominant aesthetics of the tea ceremony. Su Shi eulogized over Jian Kiln's porcelain cups many times. In the poem “Compose a Poem on Qinshi's Wall after Touring Around Buddhist Temples and Drinking Seven Cups of Tea" (游诸佛 舍一日饮酽茶七戞戯书勤师壁), Su Shi quotes the Tang Dynasty poet Lu Tong's 卢全 line "feeling elated after seven cups of tea" of "Thank Senior Expostulator Meng for His New Tea” (走笔谢孟棟议寄新茶). In another poem “Send off Master Qianshi to Mount Nanping” (送南屏谦师), Su Shi writes "Suddenly, I see the rabbit-hair pattern of the tea cup in the afternoon," which was frequently cited thereafter. Huang Tingjian's (黄庭坚) Shangu bie Ji (山谷别集) (Other Works of Huang Shangu), Liao Gang's (廖刚) Gaofeng wenji (高峰 文集) (Collected Writings of Liao Gaofeng) and Ren Yuan's (任渊) Shangu ji zhu (山谷集注) (Collected Annotations to Works of Huang Shangu) have similar descriptions. Su Shi relates the feelings of drinking tea with Jian teaware and thus contributes greatly to making the "white tea and black cup" a mainstream aesthetics in Northern Song Epoch.

On the other hand, Ouyang Xiu and Su Shi express their worries about this trend. Ouyang Xiu argues that a scholar-official like Cai Xiang should not take so many time-consuming efforts to win the favour of the emperor. Su Shi also conveys a similar view in his poems and prose. Su Shi writes in “Ode to Lichee” (荔枝叹), “Don't you see-the trees sprout new leaves on the Wuyi Stream. Ding Wei introduced the tea and Cai Xiang went further in this regard. Many officials bought new teas to please the emperor. This year tea contests soared. Alas, does the Lord really need such tea? Isn't it something evil?” Wang Shipeng (王十朋) writes in Dongpo shiji zhu (东坡诗集注) (Annotations to Poems of Su Dongpo), "The greater and lesser dragon tea was initiated by Ding Wei and further developed by Cai Xiang. Ouyang Xiu heard Cai Xiang had offered the Little Round Dragon Tea to the emperor and felt greatly surprised, 'How can he do such a thing?"' [7] Afterwards, Luo Dajing (罗大经) quotes the relevant line in Helin yulu (鹤林玉露) (Jade Dew from Crane Forest); Li Liu (李刘) and Zhu Mu (祝穆) mentioned Su Shi's line “Ding Wei introduced the tea and Cai Xiang went further in this regard" in “Mr Mei Ting's Standards for Parallel Prose" (梅亭先生四六 标准) and Fangyu shenglan (方與胜览) (Geographical
Overview) respectively. Besides, $\mathrm{Hu} \mathrm{Zi}$ (胡仔) discusses in Yuyin conghua qianji (渔隐丛话前集) (Assembled Remarks by the Fisherman Recluse of Tiao Creek: Part I) the poem.

Now it has been made clear that the Jian'an tea had indeed developed along the following trajectory in the Northern Song dynasty: first, Ding Wei introduced the Beiyuan Gardens' Tribute Tea to the court and made a drawing of the teaware in Jian'an chalu (建安茶录); second, Cai Xiang developed the Little Round Dragon Tea and promoted it to the emperor and his friends; Cai Jing modified the tea code several times and Cai Tao introduced the making of Jian tea in detail in Tieweishan congtan (铁围山丛谈). Through Cai Xiang's effort, the emperor and many officials extolled the Little Round Dragon Tea so that it became more precious than gold. [2] In the Northern Song dynasty, those scholar-officials engaged in passionate discussions on the Jian tea and the painstaking collection of relevant teaware. All these occurrences should be attributed to the efforts of Cai Xiang and his clan. In this process, Jian teaware designing and making had improved considerably.

\subsection{Materials in the Southern Song Dynasty}

\subsubsection{Chaju Tuzan (茶具图赞)}

But when it came to the Southern Song dynasty, Jian tea began to go downhill. Actually, the standards of diancha 点茶 tea-whisking and teaware became popular among common people. Chaju tuzan (茶具图赞) is a typical example. This guidebook classifies various teaware in terms of the official ranks in a funny manner, which adds a further sense of ritual to the tea-whisking of the Northern Song dynasty. But the identity of the author remains open for further debate. As Confucianism still prevailed in the Southern Song dynasty, the writer used Shen'an as his pseudonym. Nevertheless, his commendatory remarks of various pieces of teaware reveal that the author employed Confucianism as a guide to constructing the names of teaware and the correlations between them. When his thought emerged in the Southern Song dynasty, it gained widespread popularity. Ming dynasty scholar Zhu Cunli (朱存理) sighs in The Postscript to Chaju tuzan (茶具图赞),

"Teaware represents a high art so that either dukes or recluses in the Song dynasty liked these objects very much. The author writes this book about teaware to imitate great historians Sima Qian and Ban Gu. In the eyes of the author, teaware can keep the country healthy and prosperous. For this reason, I'd also like to follow the 12 masters enjoying superb mountain stream water throughout the rest time of my life. They are a great treasure indeed. Won't the Heaven give me such a chance?" [2]

Chaju tuzan (茶具图赞) enumerates all the steps in succession: zhicha (制茶) make tea-cangcha (藏茶) hoard tea-zhicha (多茶) roast tea-luonian (罗碾) sieve and grind (tea)-houtang (候汤) wait for the water-xiezhan (熁戞) warm the cup-qingjie (清洁) clean the teaware. This essentially agrees with Cai Xiang's Chalu (茶录). 
Table 1. The name of tea ware in "Chaju tuzan".

\begin{tabular}{|c|c|c|c|c|}
\hline Sequence & Name & $\begin{array}{l}\text { Courtesy } \\
\text { Name }\end{array}$ & Sobriquet & Title \\
\hline Hoard Tea & Wei honglu (韦鸿䶻) Reed Priest (Tea Roaster) & Wending & Jingyang & $\begin{array}{l}\text { Sicuhang xiansou Carefree Old Man in a Hut with } \\
\text { Four Windows }\end{array}$ \\
\hline \multirow{4}{*}{ Grind Tea } & Mu daizhi (木待制) Wood Attendant (Tea Pestle) & Liji & Wangji & Gezhu juren (隔竹居人) Recluse along the Bamboo \\
\hline & Jin facao (金法槽) Gold Judge (Tea Grinder) & $\begin{array}{l}\text { Yangu, } \\
\text { Ligu }\end{array}$ & $\begin{array}{l}\text { Yuankai, } \\
\text { Zhongkeng }\end{array}$ & $\begin{array}{l}\text { Yongzhi jiumin (雍之旧民), Past Resident of Yongzhi, } \\
\text { Heqin xiansheng } \\
\text { (和琴先生) Master Heqin }\end{array}$ \\
\hline & $\begin{array}{l}\text { Shi zhuanyun (石转运) Stone Transporter (Tea } \\
\text { Mill) }\end{array}$ & Zaochi & Chuanxing & $\begin{array}{l}\text { Xiangwu yinju (香屋隐君) Recluse in the Fragrant } \\
\text { House }\end{array}$ \\
\hline & $\begin{array}{l}\text { Hu yuanwai (胡员外) } \\
\text { Gourd Supernumerary (Tea Bail) }\end{array}$ & Weiyi & Zongxu & $\begin{array}{l}\text { Chuyue xianweng } \\
\text { (咆月仙翁) Moon-Hoarding Immortal }\end{array}$ \\
\hline \multirow{2}{*}{ Sieve Tea } & Luo shumi (罗书秘) Sieve Secretary & Ruoyao & Chuanshi & $\begin{array}{l}\text { Siyin liaozhang (思隐寮长) Chieftain with a Mind for } \\
\text { a Seclusive Life }\end{array}$ \\
\hline & Rope Retainer & Zifu & Buyi & $\begin{array}{l}\text { Saoyun xiyiou (扫云溪友) Friend of the } \\
\text { Cloud-Sweeping Stream }\end{array}$ \\
\hline \multirow{4}{*}{$\begin{array}{l}\text { 饮茶 } \\
\text { Drink/Sip } \\
\text { Tea }\end{array}$} & $\begin{array}{l}\text { Qidiao mige (漆雕秘阁) Lacquer Cabinet (Tea } \\
\text { Holder) }\end{array}$ & Chengzhi & Yichi & $\begin{array}{l}\text { Gutai laoren (古台老人) Old Man of the Ancient } \\
\text { Terrace }\end{array}$ \\
\hline & $\begin{array}{l}\text { Tao baowen (陶宝文) Pottery Academician (Tea } \\
\text { Cup) }\end{array}$ & Quyue & Zihou & $\begin{array}{l}\text { Tuyuan shangke (兔园上客) Superior Guest in Rabbit } \\
\text { Garden }\end{array}$ \\
\hline & Tang tidian (汤提) Water Inspector (Teawater Pot) & Faxin & Yiming & Wengu yilao (温古遗老) Old Adherent of the Past \\
\hline & $\begin{array}{l}\text { Zou fushuai (竺副帅) Bamboo Marshal (Tea } \\
\text { Broom) }\end{array}$ & Shantiao & Xidian & Xuetao gongzi (雪涛公子) Prince of Snow Wave \\
\hline $\begin{array}{l}\text { Clean the } \\
\text { Teaware }\end{array}$ & $\begin{array}{l}\text { Si zhifang (司职方) Cloth Superintendent (Tea } \\
\text { Cloth) }\end{array}$ & Chengshi & Rusu & Jiezhai jushi (洁斋居士) Resident of a Clean Studio \\
\hline
\end{tabular}

Some scholars claimed that Gourd Supernumerary (Bail) is used for tea whisking. [8] 15 I want to refute this opinion here for three reasons: First, Cai Xiang says clearly in Chalu (茶录), “Teaspoon should be heavy enough to break apart the teacake. Gold is the best material, and silver or iron comes next. Bamboo teaspoon is lightweight and should not be used for the Jian tea." [2] The name and drawing indicate that Gourd Supernumerary is made of gourd. Such gourd object is also lightweight and not suitable for whisking the teacake. Second, the courtesy name Weiyi (惟一) (Just or Only) seems closer to the famous Chinese saying "I would just drink a gourdful of water although the river water is beyond measure," and the title Moon-Hoarding Immortal resembles the inverted image of the moon in a water gourd. Third, Gourd Supernumerary is placed between Stone Transporter and Sieve Secretary. That does not yet fall within the stage of tea-whisking. So, did Shen'an make a mistake? The answer will be "no" because Shen'an personalizes in this book various kinds of teaware in strict accordance with Confucianism. Since water is needed during tea grinding, I consider that the Gourd Supernumerary mentioned in Chaju tuzan (茶具图赞) is actually a water bail.

Table 2. Types of tea cups in song dynasty

\begin{tabular}{|c|c|c|}
\hline Type & Name & Source \\
\hline \multirow{5}{*}{$\begin{array}{l}\text { Jian Tea Cups } \\
\text { and Their } \\
\text { Derivatives }\end{array}$} & $\begin{array}{l}\text { Rabbit-Hair } \\
\text { Pattern Cup }\end{array}$ & $\begin{array}{l}\text { “Fragrant clouds look so white on the rabbit-hair pattern cup.” See Anonym’s (佚名) Wudaishi pinghua (五代史平 } \\
\text { 话) (Popular Tales of the Five Dynasties). }\end{array}$ \\
\hline & Golden Partridge & "The Golden Partridge Pattern Cup shows the afterglow of spring." See Chao Buzhi’s (奖补之) “A Poem in the \\
\hline & Pattern Cup & Rhythm of Yifu the Prosecutor” (次韵提刑毅甫送茶). \\
\hline & Bronze-Leaf Cup & $\begin{array}{l}\text { "Your home’s bronze-leaf cup is fascinating indeed.” See Kong Zhongping’s (孔仲平) “Tea and Poem Presented } \\
\text { to Mengxi for His Ink Gift” (梦锡惠墨答以属茶). }\end{array}$ \\
\hline & $\begin{array}{l}\text { Golden Flower } \\
\text { and Bird Pattern } \\
\text { Cup }\end{array}$ & $\begin{array}{l}\text { “Golden Flower-and-Bird Pattern Cup is a vital tea object.” See Xu Jing's (徐兢) Xuanhe fengshi gaoli tujing (宣 } \\
\text { 和奉使高丽图经) (Illustrated Record of the Chinese Embassy to the Goryeo Court During the Xuanhe Era). }\end{array}$ \\
\hline Glass & Glass Cup & “Bodhisattva Manjusri took up a glass cup,” See Chan Master Yuanwu Keqin’s Biyan lu (碧䟾录). \\
\hline Small Cup & Cup & “The small cup holds together the tea fragrance.” See Lu You’s Jiannan shigao (剑南诗稿). \\
\hline Green and & Green and White & "I'll bring a pure white object to enjoy tea with you." Peng Ruli's² (彭汝砺) “Reply to Zhao Wenfu's Tea Kettle \\
\hline White Porcelain & Porcelain & Gift”(答赵温甫见谢茶瓯韵). \\
\hline White Porcelain & $\begin{array}{l}\text { White Porcelain } \\
\text { Cup }\end{array}$ & $\begin{array}{l}\text { “In Ice bowl and snow cup are placed Jianxi Tea.” } \\
\text { (Lin Jingxi’s (林景熙) “Shu Lu Fang Weng Shi Juan Hou (书陆放翁诗卷后) Inscription on Lu Fangweng's Poem } \\
\text { Scroll”) (须藉水帘泉胜乳，也容双井白过磁) } \\
\text { A curtain of water is shinier than cream and Shuangjing tea“s thin cup is whiter than porcelain. } \\
\text { (李庶《杨元忠和叶秘校腊茶诗相率偕赋》) } \\
\text { (Li Zhi’s “Write a Wax Tea Poem Along with Yang Yuanzhong and Ye Mijiao”) }\end{array}$ \\
\hline
\end{tabular}

2Peng Ruli (彭汝砺) (1042-1095), also known as Qizi, was a native of Poyang, Yaozhou (present-day Boyang, Jiangxi). In the 2nd Year (1065) of Zhiping Period of Emperor Yingzong, he was granted Graduate Scholar. In the early Yuanfeng Period, he was appointed Jiangxizhuanyunpanguan (江西转运判官) and transferred to Tidianjingxixingyu (提点京西刑狱). 


\subsubsection{Xuanhe Beiyuan Gongcha lu (宣和北苑贡茶录)}

Also, Xuanhe beiyuan gongcha lu (宣和北苑贡茶录) was written between 1182 and 1183 during the Southern Song dynasty. Xiong Fan writes this book according to his experience in the Beiyuan Tea-making during the Xuanhe Period and his son Xiong Ke add 38 drawings of teaware and specific dimensions to the book. Exactly speaking, in this book, the father and son offer a fine introduction to bamboo, silver and bronze-raided chamo (茶模) tea moulds, which makes it possible for us to look at their sizes and shapes because the real objects had vanished with the decline of the Beiyuan tea.

At present, there is little research on the aforesaid book. Three scholars explain in Zhongguo gudai chashu jicheng 中 (国古代茶书集成) (A Complete Collection of Tea Books of Ancient China) the dating, editions and content of this book, but seldom introduces those tea moulds in the book. From the Northern Song dynasty onwards, most records of the Beiyuan Gardens' Tribute Tea were scattered in poems and prose. There are few illustrated descriptions in detail available. I have imitated the drawings in this book by computer painting, which would not be further discussed here.

(i). Other Tea Types and Teaware

Despite the Jian tea and teaware's undisputable dominance in the Song dynasty, some people liked other teaware better. In the following paragraphs, I will give pieces of solid evidence. A tea object of Jian Kiln is usually large as it allows for three times of pouring water and whisking the tea. For example, the Southern Song dynasty poet Lu You (陆游) liked smaller tea cups. He writes "The small cup holds together the tea fragrance" [9] in "Come to Laughter-Asking Pavilion in the Twilight” (晚晴至索笑亭).”I In that dynasty, Buddhist venues used glass utensils in tea-drinking. Chan Master Yuanwu Keqin's (圆悟克勤) Biyan lu (碧㖘录) (Blue Cliff Record) says, "Bodhisattva Manjusri took up a glass cup, asking, 'Is it still available in the south?”” [10] Li Zhi (李廌) writes in "Write a Wax Tea Poem Along with Yang Yuanzhong and Collator-Gentleman Ye" (杨元忠和叶秘校腊茶诗相率偕 赋), “A curtain of water is shinier than cream and Shuangjing tea's thin cup is whiter than porcelain." [11] This scholar himself adds a note, "In the south, people usually used the Poyang White cup to drink Shuangjing tea."

The tea cup alone comes in various shapes. Here I provide a preliminary list of different cups according to literature of the Song dynasty:

In the Northern Song dynasty, Jian tea cup gained widespread recognition and produced many derivatives. Rabbit-hair pattern cup and partridge pattern cup are both categorized as Jian tea cup. Conversely, bronze-leaf pattern cup and golden flower-and-bird pattern cup are their derivatives. Bronze-leaf pattern cup is a yellowish brown cup similar to Jian cup. The golden flower-and-bird pattern cup is actually Goryeo's imitation of Yulinting Kilns's (遇林亭窑) product or Ding Kiln's golden flower pattern bowl. But in the Southern Song dynasty, the tea cup-making went diverse, as represented by Buddhist glass cups, Lu You's favourite chessboard pattern cups, green and white porcelain cups, and white porcelain cups.

\section{Conclusion}

Overall, the writers of the above books offer a similar sequence to the procedures of tea whisking in the Song dynasty. Yet the same step may involve different numbers of teaware due to different writers' different focuses. The materials quoted in this essay have been collected from ancient books on tea of the dynasty. According to the dynastic tea-drinking practice, the sequence is as follows: make teahoard tea-roast tea-sieve and grind (tea)-wait for the waterbroil tea-clean the teaware. For example, cup is similar to a small or shallow bowl. So, they are classified as the same object for discussion's sake.

Collecting materials on teaware of the Song dynasty indicates how much Cai Xiang and his clan contributed to spreading the dynastic teaware. This scholar-official not only developed the famous Little Round Dragon Tea, but also explained the teaware appropriate for Jian tea. Both Emperors Renzong and Huizong spoke highly of his invention. Moreover, Huizong himself even writes Daguanchalun (大观 茶论） to expound his thoughts. Cai Tao introduced in Tieweishan congtan (铁围山丛谈) the making of Jian tea. Cai Jing enacted The Law of Tea Containers that stipulates the official standards for such containers. This law was still valid in the Southern Song dynasty. Through the effort of the clan of Cai and under the aegis of the Northern Song regime, Jian teaware had become extremely famous and used widely by various classes of the society. Such massive promotion was scarcely found in any other period of Chinese history. Unfortunately, this craze declined increasingly in the Southern Song dynasty and disappeared completely in the subsequent Yuan dynasty. There are merely three extant Jian teaware enshrined at Seikadō Bunko Art Museum, Ryukoin sub-temple of the Daitokuji and Fujita Art Museum in Osaka, all of which showcase the sheer might that the Song regime had shown through engaging in teaware-making and teaware aesthetic appraisal.

Also, tea thoughts of the Song dynasty influenced Goryeo and Japan. As its name tells, Xuanhe fengshi gaoli tujing (宣 和奉使高丽图经) is a record of the Song dynasty official Xu Ke's (徐克) (1091-1153) trip to the country. This travelogue shows us how the Song dynasty's teaware were introduced and modelled in Goryeo. Album of a Tea Peddler's Teaware (卖茶翁茶器图) was created by Japanese painter Kimura Koyo. In the 15th Year of the Showa Era (1940), Ichishima Kenji donated the album to Waseda University. Tea Peddler is the title of Kō Yūgai (Gekkai Genshō) who revived sencha (煎 茶) in the Edo Period of Japan. And sencha owes its origin to Chajing (茶经). In the Southern Song dynasty, Zen monk Eisai brought tea seeds and tea art back to Japan, where sencha (煎茶) came into being and has been popular to this day. 


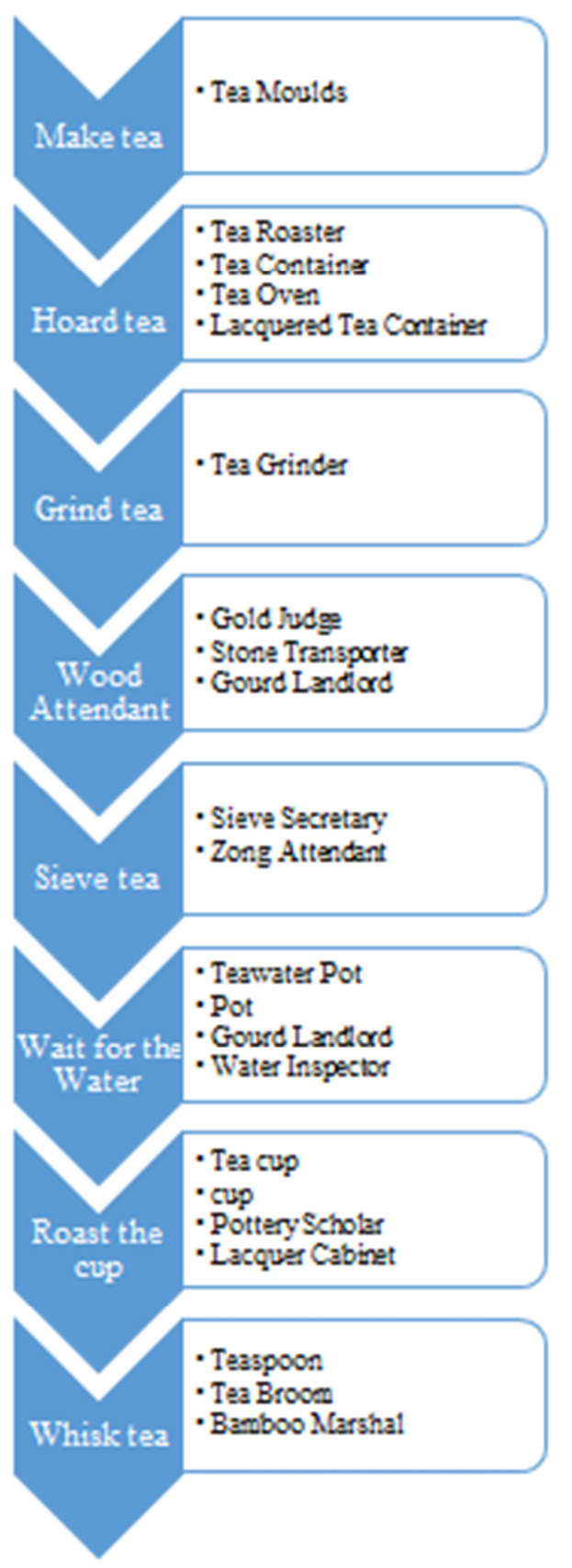

Figure 1. Song dynasty tea corpus
Through the effort of Cai Xiang and his clan, teaware-making reached a new height in the Song dynasty. Though his effort is seldom mentioned, the well-preserved objects from Jian Kiln at home and abroad imply that such governmental involvement made a great success in teaware design and making.

\section{Acknowledgements}

This research was supported by the Ministry of Education Social Sciences Foundation of China under grant No. 19YJC760050.

\section{References}

[1] Ronald Egan, The Problem of Beauty (Cambridge: Harvard University Asia Center, 2006).

[2] Zizhen, Zhu, Dongmei Shen, and Qin Zeng. Zhongguo gugai chashu jichen. Shanghai: Shanghai wenhua chubanshe, 2017.

[3] Yaochen, Mei. Wanling ji. Taiwan: Taiwan commercial press, 1984.

[4] Su Xiangxian, Chengxiang weigong tanxun (Shanghai: Shanghai commercial press, 1936).

[5] Hu Shunzhi. Hu shaoshi zong Ji, Xuxiu siku quanshu edition (Shanghai: Shanghai ancient books publishing house, 2002), 1317 juan.

[6] Fu, Liu. Qingsuo gaoyi qianji. Taiwan: Taiwan xinxing shuju youxian gongsi, 1928.

[7] Shipeng, Wang. Dongpo shiji zhu. Taiwan: Taiwan commercial press, 1984.

[8] Hsin-Yi Chu, "A Study of "Chaju tuzan", Journal of the Chinese Department, National Chung Hsing University, 35 (2008).

[9] You, Lu. Jiannan shigao. Taiwan: Taiwan commercial press, 1984.

[10] Wu, Yuan. Biyan lu. Translated into modern Chinese by Xu Wengong. Beijing: Huaxia chubanshe, 2009.

[11] Li Zhi. Jinan ji, WYGSKQSedition (Taiwan: Taiwan commercial press, 1984). 